\title{
PAN SHARPENING QUALITY INVESTIGATION OF TURKISH IN-OPERATION REMOTE SENSING SATELLITES: APPLICATIONS WITH RASAT AND GÖKTÜRK-2 IMAGES
}

\author{
Mustafa Ozendi a *, Hüseyin Topan ${ }^{\text {a }}$, Ali Cam ${ }^{\text {a }}$, Çağlar Bayık ${ }^{\text {a }}$ \\ ${ }^{a}$ BEU, Engineering Faculty, Department of Geomatics Engineering, 67100 Zonguldak, Turkey - (mustafa.ozendi, topan, \\ caglarbayik)@beun.edu.tr, alicam193@gmail.com
}

Commission VII, WG VII/6

KEY WORDS: RASAT, GÖKTÜRK-2, IHS, Brovey, PCA, Correlation Coefficient, RMSE, RASE, SAM, ERGAS

\begin{abstract}
:
Recently two optical remote sensing satellites, RASAT and GÖKTÜRK-2, launched successfully by the Republic of Turkey. RASAT has $7.5 \mathrm{~m}$ panchromatic, and $15 \mathrm{~m}$ visible bands whereas GÖKTÜRK-2 has $2.5 \mathrm{~m}$ panchromatic and $5 \mathrm{~m}$ VNIR (Visible and Near Infrared) bands. These bands with various resolutions can be fused by pan-sharpening methods which is an important application area of optical remote sensing imagery. So that, the high geometric resolution of panchromatic band and the high spectral resolution of VNIR bands can be merged. In the literature there are many pan-sharpening methods. However, there is not a standard framework for quality investigation of pan-sharpened imagery.
\end{abstract}

The aim of this study is to investigate pan-sharpening performance of RASAT and GÖKTÜRK-2 images. For this purpose, pansharpened images are generated using most popular pan-sharpening methods IHS, Brovey and PCA at first. This procedure is followed by quantitative evaluation of pan-sharpened images using Correlation Coefficient (CC), Root Mean Square Error (RMSE), Relative Average Spectral Error (RASE), Spectral Angle Mapper (SAM) and Erreur Relative Globale Adimensionnelle de Synthése (ERGAS) metrics. For generation of pan-sharpened images and computation of metrics SharpQ tool is used which is developed with MATLAB computing language. According to metrics, PCA derived pan-sharpened image is the most similar one to multispectral image for RASAT, and Brovey derived pan-sharpened image is the most similar one to multispectral image for GÖKTÜRK-2. Finally, pansharpened images are evaluated qualitatively in terms of object availability and completeness for various land covers (such as urban, forest and flat areas) by a group of operators who are experienced in remote sensing imagery.

\section{INTRODUCTION}

Optical based remote sensing satellites are capable of acquiring MS (multispectral) and Pan (panchromatic) images covering same portion of the ground simultaneously. While MS images provide high spectral resolution, their geometric resolution is always lower when compared with PAN images. In order to generate MS images with high geometric resolution using these images, pan-sharpening or so called image fusion methods are developed. There are numerous pan-sharpening methods developed by remote sensing, computer vision and image processing communities and research is still going on to develop a pan-sharpening method which reveals the most optimum results. (Pohl and Van Genderen, 1998), (Karathanassi et al., 2007) and (Ehlers et al., 2010) have presented comprehensive literature review on pan-sharpening methods used for remote sensing.

Performance of each image fusion method is different. Some of them keep spatial information. On the other hand, some of them are focused on keeping colour information. Because of this reason, quality of images generated by image fusion should be performed both quantitatively and visually (Klonus and Ehlers, 2009)

Statistical metrics such as Correlation Coefficient (CC), Root Mean Square Error (RMSE), Relative Average Spectral Error (RASE), and Spectral Angle Mapper (SAM) can be used for quantitative quality assessment (Alparone et al., 2007). Thanks to these statistical metrics, similarity between the pan-sharpened image and original MS image and the spectral quality can be determined. This approach for quality assessment is used in many studies. For details, works presented by Tsai (2004), Zhang (2008), Khan et al. (2008), Chen et al. (2008), Klonus and Ehlers (2009), Makarau et al. (2012), Yuhendra et al. (2012), Yusuf et al. (2013) and Sarp (2014) can be referred.

Aforementioned works require a reference data which is generally a reference image at the same resolution with pansharpened images. Quality Not requiring a Reference (QNR) proposed by (Alparone et al., 2008) and the approach proposed by (Khan et al., 2009) which takes advantage of Modulation Transfer Functions of Instruments are examples for quality evaluation not requiring reference data.

Visual quality assessment is performed with the help of an operator in terms of existence and completeness of objects (Laporterie-Déjean et al., 2005). The work presented by (Yang et al., 2012) aims determining spectral quality of fused images both qualitatively and quantitatively, in which CC, relative difference to mean (RDM) and relative difference standard deviation (RDS) are employed.

In this study, we aim to analyse pan-sharpening performance of RASAT and GÖKTÜRK-2. For this purpose, we used SharpQ tool developed by (Ozendi et al., 2015) which is capable of generating pan-sharpened images using PCA (Principal Component Analysis), IHS (Intensity Hue Saturation) and Brovey transform algorithms. This tool is also capable of calculating quality metrics CC, RASE, SAM, RMSE and ERGAS after generating the pan-sharpened images. This study was presented at VI. UZAL-CBS symposium held in Adana Turkey at October 2016 for the national community.

\footnotetext{
* Corresponding author
} 


\section{DATA-SET AND TEST SITE}

Following the experience with Bilsat, RASAT launched at 17 August 2011 is the first Earth-observation satellite designed and built in Turkey. The RASAT images can be downloaded from GEZGIN portal free-of-charge for Turkish citizens. Technical specification of RASAT are given in Table 1.

\begin{tabular}{|l|l|}
\hline Altitude & $\sim 700 \mathrm{~km}$ \\
\hline Spatial Resolution & PAN 7.5m - RGB 15m \\
\hline Swath Width & $30 \mathrm{~km}$ \\
\hline Radiometric Resolution & 8 bit \\
\hline Temporal Resolution & 4 days \\
\hline
\end{tabular}

Table 1. Technical specifications of RASAT

GÖKTÜRK-2 is the first high resolution Earth-observation satellite of Turkey which is built by cooperation of Turkish Aerospace Industries, Inc. (TAI) and TÜBITTAK Space. The governmental agencies and research/education institutions may order GÖKTÜRK-2 images from Turkish Air Forces free-ofcharge. Technical specifications of GÖKTÜRK-2 are tabulated in Table 2.

\begin{tabular}{|l|l|}
\hline Altitude & $\sim 700 \mathrm{~km}$ \\
\hline Spatial Resolution & PAN $2.5 \mathrm{~m}-$ RGB-NIR 5m \\
\hline Swath Width & $20 \mathrm{~km}$ \\
\hline Radiometric Resolution & 11 bit \\
\hline Temporal Resolution & $2-3$ days \\
\hline
\end{tabular}

Table 2. Technical specifications of GÖKTÜRK-2

The research was performed in Zonguldak (Turkey) test site. So far, various kinds of aerial and spaceborne remotely sensed optical and microwave images were analysed with respect to geospatial potential in this particular test site. A scene of Zonguldak test field and city centre can be shown in Figure 1.

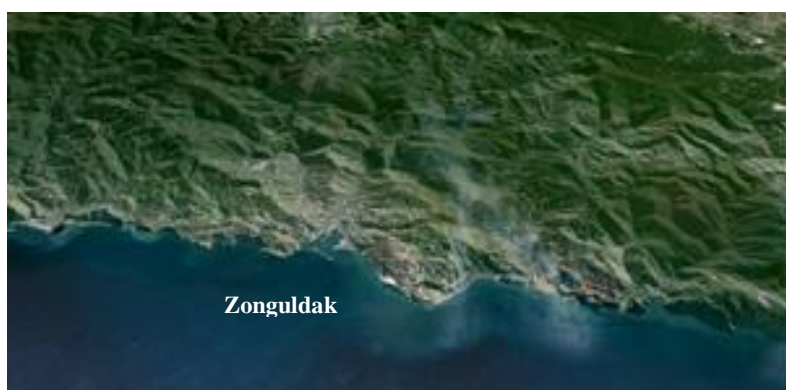

Zonguldak city centre and its inland

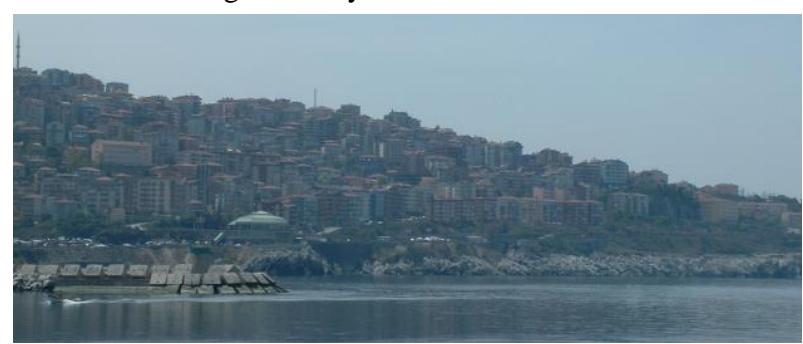

A scene from Zonguldak city centre

Figure 1. Zonguldak test site (Turkey).

The main characteristics of this test site are its mountainous and extremely undulating topography, dense forest and agricultural areas, various water bodies, such as rivers, sea, and dams, open and underground mining areas, thermal power stations as well as iron and steel plants, etc. The Zonguldak city centre was also settled on this undulating mountainous topography. Due to these properties, Zonguldak is a very suitable test site for performance evaluation of remote sensing platforms.

Three different pan-sharpened images were generated for RASAT and GÖKTÜRK-2 Level 1 images (Figure 2) using SharpQ tool. Pan-sharpened images were generated using PCA, IHS and Brovey transform algorithms. Even though there are numerous pan-sharpening algorithms, these three methods were used for generation of pan-sharpened images. The main reason is that these methods are the most common and also mostly preferred ones by the commercial remote sensing softwares. Generated images for RASAT and GÖKTÜRK-2 satellites are presented in Figure 3.

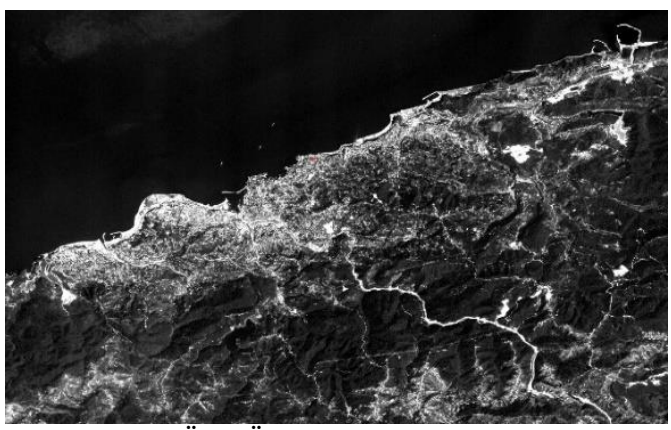

GÖKTÜRK-2 panchromatic
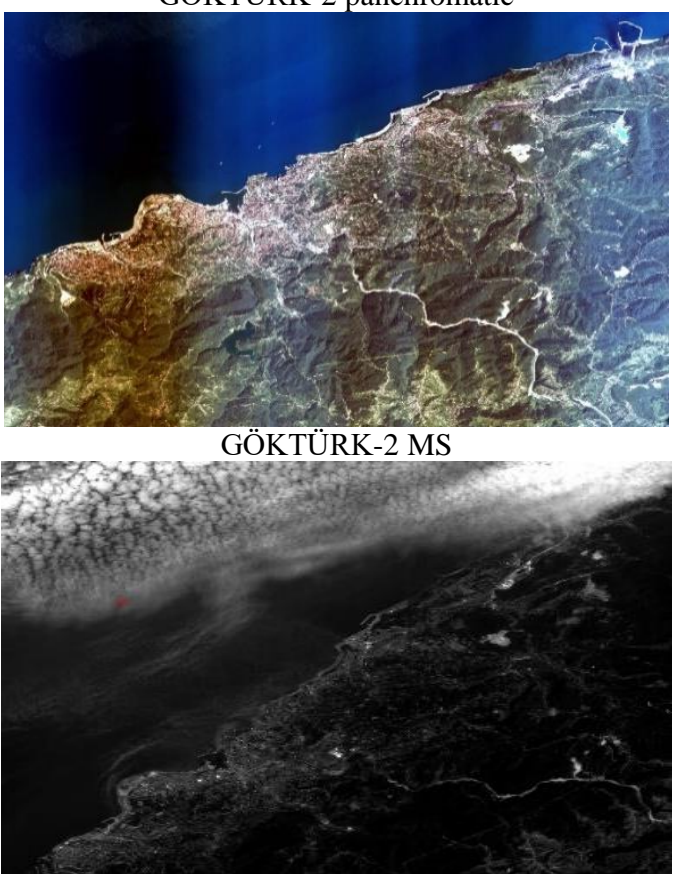

RASAT panchromatic

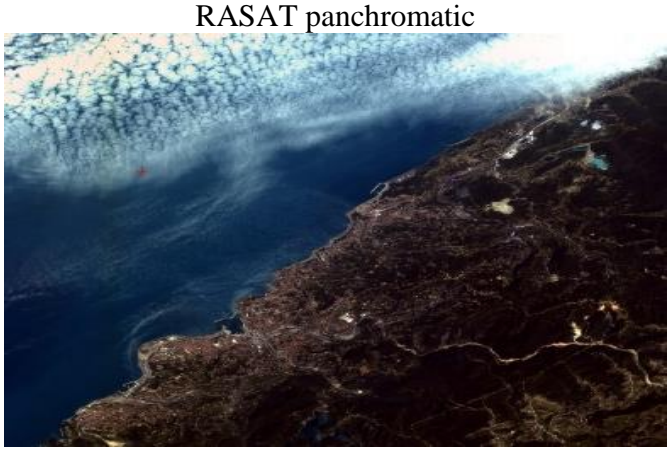

RASAT MS

Figure 2. GÖKTÜRK-2 and RASAT images in Level 1. 
Generally speaking, pan-sharpened images were generated from Level 1 images which were generated from the original images (Level 0) adjusting the variation of detector responses (Atak et al., 2015). Despite this adjustment process, the variation of detector responses are still available in GÖKTÜRK-2 pansharpened images (Figure 2). On the other hand, for RASAT pansharpened images effect of detector responses is not as obvious as in GÖKTÜRK-2 pan-sharpened images. Radiometric calibration studies were carried out after we received these images (Teke et al., 2016).

\section{QUANTITATIVE EVALUATION}

As obvious from Figure 2, there are some differences in terms of spatial and spectral properties of pan-sharpened images when compared to original PAN and MS images. Similarity of pansharpened images to original Pan and MS images can be determined statistically using well-known metrics. In this study, commonly used quality metrics including CC, RMSE, RASE, SAM and ERGAS are used. Following sections report results of metrics on RASAT and GÖKTÜRK-2 images respectively.
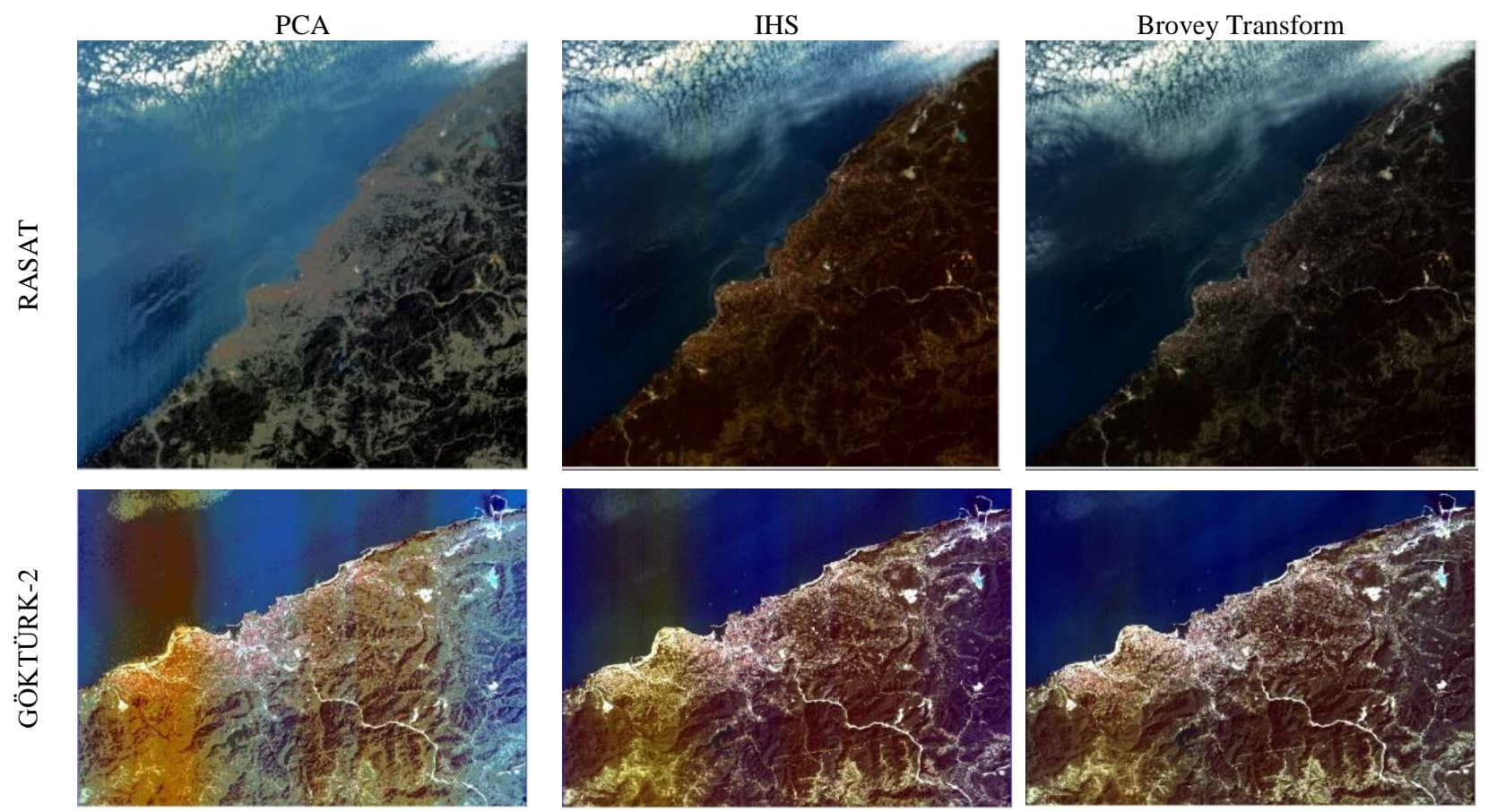

Figure 3. Pan-sharpened images. RASAT pan-sharpened images ( $1^{\text {st }}$ row). GÖKTÜRK-2 pan-sharpened images ( $2^{\text {nd }}$ row).

\subsection{Quantitative Evaluation of RASAT Pan-sharpened Images}

Computation of CC, RASE, SAM, RMSE and ERGAS metrics are performed using SharpQ, which is presented in (Ozendi et al., 2015). These metrics were calculated for each pan-sharpened image as the original MS image was taken as the reference dataset. Results of metrics for RASAT pan-sharpened image are tabulated in Table 3 where values are shown in three different colours. Grey represents the optimal results, which implies that two images are exactly same. Green represents the best results which means pan-sharpened and MS images are the closest to each other. And finally, red represents the worst results meaning that images are the least similar to each other.

\begin{tabular}{|c|c|c|c|c|c|}
\cline { 2 - 6 } \multicolumn{1}{c|}{} & CC & RMSE & RASE & SAM & ERGAS \\
\cline { 2 - 6 } \multicolumn{1}{c|}{} & 1 & 0 & 0 & 0 & 0 \\
\hline PCA & 0.8481 & 3325.70 & 2359.068 & 0.0996 & 1186.342 \\
\hline IHS & 0.9705 & 7691.00 & 5674.016 & 0.3206 & 2686.754 \\
\hline Brovey & 0.9724 & 14119.00 & 10095.99 & 0.0076 & 4869.667 \\
\hline & Optimal Value \\
Best Value \\
Worst Value
\end{tabular}

Table 3. Metric results for RASAT pan-sharpened images According to Table 3, speaking statistically, PCA method resulted in the most consistent pan-sharpened image. On the other hand, the pan-sharpened image generated with IHS method resulted in the least similar image.

\subsection{Quantitative Evaluation of GÖKTÜRK-2 Pan- Sharpened Images}

For GÖKTÜRK-2 pan-sharpened images, same procedure is followed as in Section 3.1 and computed metric results are shown in Table 4.

\begin{tabular}{|c|c|c|c|c|c|}
\hline & $\mathrm{CC}$ & RMSE & RASE & SAM & ERGAS \\
\hline & 1 & 0 & 0 & 0 & 0 \\
\hline PCA & 0.861 & $5.49 \times 10^{4}$ & 31279.76 & 0.677 & 11170.16 \\
\hline IHS & 0.866 & $5.18 \times 10^{4}$ & 28665,06 & 0.329 & 10483,63 \\
\hline Brovey & 0.582 & $3.56 \times 10^{4}$ & 19338.17 & 0.003 & 7195.65 \\
\hline
\end{tabular}

Table 4. Metric results for GÖKTÜRK-2 images

Taking Table 4 into account, it can be inferred that the pansharpened image generated with Brovey transform method resulted in the most consistent image with MS image. However, the image generated by PCA method is the least similar image with MS image statistically. 
According to Table 3 and 4, while PCA generated the most consistent image for RASAT, it resulted in the least consistent image for GÖKTÜRK-2. The findings can be concluded below:

a) When the metrics were reviewed, it can be said that RASE and ERGAS depends on the RMSE. Because of this fact, RASE and ERGAS yield to similar results.

b) The CC resulted in best for GÖKTÜRK-2 product because the detector response effect is available both in original MS and pan-sharpened image.

c) For RASAT, PCA seems to be the best method w.r.t. RMSE, RASE and ERGAS metrics, which are depending on the grey value differences between original MS and pan-sharpened images. However, visual interpretation should be performed for more accurate comparison.

\section{QUALITATIVE EVALUATION}

GÖKTÜRK-2 images have higher GSD and spectral resolution when compared to RASAT. As a result of this fact, in terms of visual quality evaluation GÖKTÜRK-2 is superior to RASAT. Visual quality assessment was performed by a group of operators who are experienced at remote sensing images. A sample part of test field in generated pan-sharpened images can be seen in Figure 4.
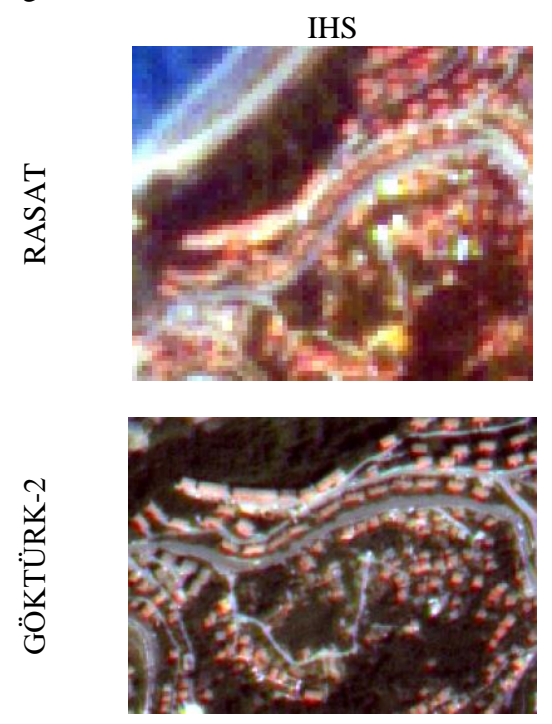

This assessment procedure is carried out according to criteria given in Table 5 . When Table 5 is taken into account the following inferences can be made:

- $\quad$ PCA results in the worst pan-sharpened images for both RASAT and GÖKTÜRK-2.

- As mentioned before, detector response effect is available in original RASAT and GÖKTÜRK-2 images. While this effect is available in all pan-sharpened images, it is almost not available in Brovey pan-sharpened image of GÖKTÜRK-2.

- Considering naturality of pan-sharpened images, Brovey transform generates most natural images.

- Discrimination of land cover types is an important application area of remote sensing. Land cover discrimination is more successful for IHS and Brovey methods.

- Object recognition is investigated for road network and single building recognition performances of pan-sharpened images. Using RASAT pan-sharpened images, only highways can be recognized. On the other hand, it is possible to recognize the entire road network using GÖKTÜRK-2 pan-sharpened images.

Figure 4. A sample part of the test field in pam-sharpened images

\begin{tabular}{|c|c|c|c|c|c|c|}
\hline & & $\begin{array}{l}\text { Detector response } \\
\text { effect }\end{array}$ & $\begin{array}{l}\text { Natural } \\
\text { view }\end{array}$ & $\begin{array}{l}\text { Land cover } \\
\text { discrimination }\end{array}$ & $\begin{array}{l}\text { Road network } \\
\text { recognition }\end{array}$ & Single object recognition \\
\hline \multirow{3}{*}{ 究 } & PCA & Available & Worst & Coarsely possible & Only highways & Not possible \\
\hline & IHS & Better than PCA & $\begin{array}{l}\text { Better } \\
\text { than PCA }\end{array}$ & Better than PCA & Better than PCA & Objects can be clustered \\
\hline & Brovey & $\begin{array}{l}\text { Better than PCA, } \\
\text { almost equal to IHS }\end{array}$ & Best & $\begin{array}{l}\text { Better than PCA, } \\
\text { almost equal to IHS }\end{array}$ & $\begin{array}{l}\text { Almost equal to } \\
\text { IHS }\end{array}$ & Objects can be clustered \\
\hline \multirow{3}{*}{ 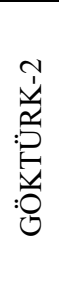 } & PCA & Available & Worst & Possible & $\begin{array}{l}\text { Entire road } \\
\text { network can be } \\
\text { recognized }\end{array}$ & $\begin{array}{l}\text { Buildings can be } \\
\text { counted, but boundaries } \\
\text { cannot be recognised }\end{array}$ \\
\hline & IHS & Available & $\begin{array}{l}\text { Better } \\
\text { than PCA }\end{array}$ & Better than PCA & Better than PCA & $\begin{array}{l}\text { Building boundaries can } \\
\text { be recognised clearly }\end{array}$ \\
\hline & Brovey & $\begin{array}{l}\text { Almost not } \\
\text { available }\end{array}$ & Best & Almost equal to IHS & $\begin{array}{l}\text { Almost equal to } \\
\text { IHS }\end{array}$ & $\begin{array}{l}\text { Building boundary } \\
\text { recognition is worse than } \\
\text { IHS }\end{array}$ \\
\hline
\end{tabular}

Table 5. Visual quality assessment criteria and results. 


\section{CONCLUSIONS}

In this paper, pan-sharpening quality of RASAT and GÖKTÜRK-2 images was investigated. For generation of pansharpened images IHS, PCA and Brovey transform methods were used. These images were investigated quantitatively using statistical metrics and qualitatively with a group of operators experienced in remote sensing images.

Detector response effect, which is available in original images, is also available in pan-sharpened images. However, this effect is almost unavailable in GÖKTÜRK-2 pan-sharpened image generated with Brovey transform. GSD and radiometric resolution of an image play important role in visual recognition of objects. Because of this fact, object recognition is more successful at GÖKTÜRK-2 pan-sharpened images. As a result of quantitative and qualitative assessment of pan-sharpened images, Brovey Transform and IHS method generates better images.

\section{ACKNOWLEDGEMENTS}

Authors would like to thank to Turkish Air Force for GÖKTÜRK-2 images.

\section{REFERENCES}

Alparone, L., Aiazzi, B., Baronti, S., Garzelli, A., Nencini, F., Selva, M., 2008. Multispectral and Panchromatic Data Fusion Assessment Without Reference. Photogramm Eng Rem S 74, 193-200.

Alparone, L., Wald, L., Chanussot, J., Thomas, C., Gamba, P., Bruce, L.M., 2007. Comparison of Pansharpening Algorithms: Outcome of the 2006 GRS-S Data-Fusion Contest. Ieee T Geosci Remote 45, 3012-3021.

Atak, V.O., Erdoğan, M., Y1lmaz, A., 2015. Göktürk-2 Uydu Görüntü Testleri. Harita Dergisi 153.

Chen, S.H., Su, B., Zhang, H., 2008. Feature space and metric measures for fusing multisensor images. Int J Remote Sens 29 , $3257-3270$

Ehlers, M., Klonus, S., Johan Åstrand, P., Rosso, P., 2010. Multisensor image fusion for pansharpening in remote sensing. International Journal of Image and Data Fusion 1, 25-45.

Karathanassi, V., Kolokousis, P., Ioannidou, S., 2007. A comparison study on fusion methods using evaluation indicators. Int J Remote Sens 28, 2309-2341.

Khan, M.M., Alparone, L., Chanussot, J., 2009. Pansharpening Quality Assessment Using the Modulation Transfer Functions of Instruments. Ieee T Geosci Remote 47, 3880-3891.

Khan, M.M., Chanussot, J., Condat, L., Montanvert, A., 2008. Indusion: Fusion of Multispectral and Panchromatic Images
Using the Induction Scaling Technique. Ieee Geosci Remote $S$, 98-102.

Klonus, S., Ehlers, M., 2009. Performance of evaluation methods in image fusion, 12th International Conference on Information Fusion, Seattle, WA, USA.

Laporterie-Déjean, F., de Boissezon, H., Flouzat, G., LefèvreFonollosa, M.-J., 2005. Thematic and statistical evaluations of five panchromatic/multispectral fusion methods on simulated PLEIADES-HR images. Information Fusion 6, 193-212.

Makarau, A., Palubinskas, G., Reinartz, P., 2012. Selection of numerical measures for pan-sharpening assessment, 2012 IEEE International Geoscience and Remote Sensing Symposium, pp. 2264-2267.

Ozendi, M., Topan, H., Oruc, M., Cam, A., 2015. Pan-sharpening quality investigation of PLÉIADES-1A images. Geocarto International, 1-10.

Pohl, C., Van Genderen, J.L., 1998. Review article Multisensor image fusion in remote sensing: Concepts, methods and applications. Int J Remote Sens 19, 823-854.

Sarp, G., 2014. Spectral and spatial quality analysis of pansharpening algorithms: A case study in Istanbul. Eur J Remote Sens 47, 19-28.

Teke, M., Demirkesen, C., Haliloğlu, O., İmre, E., 2016. Göktürk-2 Uydusunun Bağıl ve Mutlak Çapraz Radyometrik Kalibrasyonu. Harita Dergisi.

Tsai, V.J.D., 2004. Evaluation of multiresolution image fusion algorithms, Geoscience and Remote Sensing Symposium, 2004. IGARSS '04. Proceedings. 2004 IEEE International, pp. 1-624.

Yang, B., Kim, M., Madden, M., 2012. Assessing Optimal Image Fusion Methods for Very High Spatial Resolution Satellite Images to Support Coastal Monitoring. GIScience \& Remote Sensing 49, 687-710.

Yuhendra, Alimuddin, I., Sumantyo, J.T.S., Kuze, H., 2012. Assessment of pan-sharpening methods applied to image fusion of remotely sensed multi-band data. International Journal of Applied Earth Observation and Geoinformation 18, 165-175.

Yusuf, Y., Sri Sumantyo, J.T., Kuze, H., 2013. Spectral information analysis of image fusion data for remote sensing applications. Geocarto International 28, 291-310.

Zhang, Y., 2008. Methods for image fusion quality assessment-a review, comparison and analysis. The International Archives of the Photogrammetry, Remote Sensing and Spatial Information Sciences 37, 1101-1109. 